\title{
Audit of Physicians' Adherence to the Antibiotic Policy Guidelines in Kuwait
}

\author{
Nasser Y. Aly ${ }^{a, c}$ Abeer A. Omar ${ }^{a, e}$ Dina A. Badawy ${ }^{a, f}$ Haifa H. Al-Mousa ${ }^{a}$ \\ Ali A. Sadek ${ }^{b, d}$ \\ Directorates of anfection Control and ${ }^{b}$ Health Information and Medical Records, Ministry of Health, Kuwait City, \\ Kuwait; Departments of ${ }^{\mathrm{C}}$ Tropical Medicine and Hygiene, ${ }^{\mathrm{d} C o m m u n i t y ~ M e d i c i n e, ~ F a c u l t y ~ o f ~ M e d i c i n e, ~ a n d ~}$ \\ eMicrobiology, High Institute of Public Health, University of Alexandria, Alexandria, and ${ }^{\mathrm{f} D e p a r t m e n t}$ of Clinical \\ Pathology, Faculty of Medicine, Ain Shams University, Cairo, Egypt
}

\section{Key Words}

Antibiotic policy guidelines, adherence $\cdot$ Rational

prescribing $\cdot$ Kuwait

\begin{abstract}
Objective: To audit physicians' adherence to the local antibiotic policy guidelines in government hospitals in Kuwait. Materials and Methods: The study was a retrospective review of patient records in nine hospitals between July 1 and December 31, 2008. Clinical notes and medication charts of the latest hospital admissions were checked for antibiotic prescribing. On the audit form, aspects of the prescribed antibiotic were benchmarked to the hospital antibiotic policy guidelines to evaluate adherence. Results: Of 2,232 reviewed records, 1,112 (49.8\%) patients had 1,528 antibiotic prescriptions. Patients who received antibiotics were significantly younger than those who did not (median age: 26.3 vs. 29.8 years, $p<0.001$ ) and their hospital stay was significantly longer (median: 4 vs. 2 days, $p<0.001$ ). The choice of an antibiotic was appropriate and matched the policy in 806 (52.7\%) prescriptions. Of such appropriate antibiotics, adherence to route of administration was observed in 768/806 (95.3\%), to dose in 758 (94\%), to frequency in $746(92.6 \%)$ and to duration in 608 (75.4\%). Full adherence to all aspects of antibiotic
\end{abstract}

choice, dose, route, frequency and duration was achieved in 464 (30.4\%) prescriptions. In 382 (25\%), the antibiotics administered were not indicated. Conclusion: There was low adherence to the local antibiotic policy guidelines. Physicians' antibiotic prescribing practices should be optimized. Adherence to, and update of, the policy is recommended.

Copyright $\odot 2012$ S. Karger AG, Basel

\section{Introduction}

The role of antibiotic policies is to guide physicians to prescribe all-appropriate antibiotics, avoid unjustified prescription, reduce the emergence of antibiotic-resistant bacteria, support high-quality clinical practice and minimize unnecessary expenses [1-3]. The implementation of evidence-based guidelines for use of antimicrobials had been shown to improve the overall patient outcome. Studies $[4,5]$ have established the efficacy of surgical antibiotic prophylaxis for reducing the risk of postoperative wound infection. Others have consistently shown an association between timely start of antibiotics for patients with serious infections and a favorable clinical outcome [6-8].

\section{KARGER}

Fax +4161306 1234

E-Mail karger@karger.ch

www.karger.com
(C) 2012 S. Karger AG, Basel

$1011-7571 / 12 / 0214-0310 \$ 38.00 / 0$

Accessible online at:

www.karger.com/mpp
Nasser Y. Aly

Directorate of Infection Control, Ministry of Health

PO Box 12414

Al-Shamiya 71655 (Kuwait)

Tel. +965 488 8000/3816, E-Mail nasseryehia@gmail.com 
Successful implementation of an antibiotic policy is as important as development of the policy itself. However, previous studies have shown that adherence to policy recommendations has been suboptimal averaging $40 \%$ [9-11]. In this perspective, three main types of interventions are known to improve antibiotic prescribing in hospitals: (a) persuasive interventions, which focus on the educational standpoints; these include educational materials, meetings or outreach visits, local consensus processes, local opinion leaders, verbal, written or computer-based reminders as well as audits and feedback; (b) restrictive interventions which include selective reporting of laboratory susceptibilities, formulary restriction, requiring prior authorization of prescriptions by infectious disease physicians, microbiologists, pharmacists etc., therapeutic substitutions, automatic stop orders and antibiotic policy change strategies; (c) structural interventions which shift antibiotic prescribing from paper to computerized records and introduce quality monitoring mechanisms [12].

In Kuwait, a panel of multidisciplinary expert staff had drafted antibiotic policies in government hospitals almost since 1985 and were subject to regular update. However, such policies first appeared as printed pocketsize booklets in 2005 and the national antibiotic policy was printed in 2007. The national policy was distributed via the Infection Control Directorate to infection control departments in the hospitals. The infection control physicians forwarded the copies to the physicians via the heads of departments and were requested to sign a form to ensure that they received their copies. The national policy contains the broad evidence-based guidelines for prescription of antibiotics. In addition, every hospital has its own policy, which is a booklet gathering antibiotic policies from all departments based on the national policy. The hospital policy is formulated through antibiotic committee which includes representatives from the clinical departments, clinical microbiology, pharmacy and the infection control physicians as a coordinator.

Whether or not the antibiotic guidelines included in the policy are effectively applied in clinical practice has been open to question. So far, there is no available data on adherence to the local hospital antibiotic policy guidelines in Kuwait. Collection and analysis of such data are important before starting any program or campaign to promote the prudent use of antibiotics. Initially, we conducted a prestudy pilot survey on 90 records; of these 40 (44.4\%) contained antibiotic prescriptions. The pilot survey aimed to examine the aptness of the designed audit form, explore difficulties (e.g. temporary nonexistence of some patients' records during the data collection phase) and estimate the time needed for completion of the audit. Records of the pilot study were not included in the final sample. The aim of the present research was to measure physicians' adherence to the local hospital antibiotic policy guidelines in nine government hospitals.

\section{Materials and Methods}

\section{Design and Setting}

The study was a retrospective review of medical records, which was conducted over a 6-month period (July 2008 to December 2008) in nine government hospitals; four of six general hospitals and five of nine specialized hospitals were chosen at random. The characteristics of these hospitals are shown in table 1 . Records selected for review belonged to patients discharged from the hospitals in 2007. Because the medical records of 2007 were complete at the beginning of this study, the database of 2007 was used for case selection. Data as defined below were first stratified according to hospital. Then the suggested sample size $(n=2,300)$ was selected by proportional allocation randomly.

\section{Ethical Consideration}

The Standing Committee for Coordination of Health and Medical Research at the Ministry of Health, Kuwait, approved the study.

\section{Audit Form}

A precoded audit data collection form was designed to collect the data from medical records. The form was designed by four infection control physicians and was discussed with clinical microbiologists and statisticians. In each record, the most recent hospital admission was checked for antibiotic prescribing. The following data were recorded: patients' demographics, hospital name, unit specialty, date of last admission and discharge, the clinical diagnosis, availability of reasons/indications for prescribing, and the antibiotic-related information. Data for diagnosis were extracted from the clinical notes (symptoms and signs) of the physicians and nurses, laboratory and radiological investigations, microbiological culture and sensitivity reports and medication charts.

On the audit form, the reason/indication for prescribing antibiotics was checked and included: (a) definite or presumed diagnosis of a bacterial infection; the infections were grouped according to the standard method of grouping healthcare-associated infections as described by the Centres for Disease Control and Prevention [13]; (b) medical prophylaxis (e.g. infective endocarditis); (c) preoperative surgical prophylaxis; (d) irrational prescription for a noninfectious condition (e.g. uncomplicated bronchial asthma) or a nonbacterial infection (e.g. viral infection); (e) unclear, i.e. the information provided in the record was not sufficient to claim specific diagnosis.

\section{Assessment of Adherence to the Policy}

We proceeded by identifying the reason for antibiotic prescribing if any, checking indications and evaluating the appropri- 
Table 1. Characteristics of the study hospitals

\begin{tabular}{|c|c|c|c|c|c|c|}
\hline Hospital name & $\begin{array}{l}\text { Bed } \\
\text { capacity }\end{array}$ & $\begin{array}{l}\text { Bed } \\
\text { occupancy, } \\
\%\end{array}$ & $\begin{array}{l}\text { Hospital } \\
\text { discharges }\end{array}$ & $\begin{array}{l}\text { Reviewed } \\
\text { records } \\
(\mathrm{n}=2,232)\end{array}$ & $\mathrm{n}$ & $\%$ \\
\hline \multicolumn{7}{|c|}{ General (secondary care) hospital } \\
\hline Farwaniya & 650 & 64.6 & 28,444 & 593 & 242 & 40.8 \\
\hline Al-Sabah & 449 & 61.4 & 18,972 & 371 & 250 & 67.4 \\
\hline \multicolumn{7}{|c|}{ Specialized (tertiary care) hospital } \\
\hline Maternity & 375 & 69.9 & 20,233 & 286 & 140 & 49.0 \\
\hline Ibn Sina ${ }^{b}$ & 246 & 52.0 & 7,148 & 131 & 47 & 35.9 \\
\hline $\mathrm{Al}-\mathrm{Bahr} \mathrm{r}^{\mathrm{c}}$ & 74 & 31.0 & 2,056 & 44 & 19 & 43.2 \\
\hline Hamad Al-Eissa $^{\mathrm{d}}$ & 39 & 55.0 & 1,458 & 44 & 17 & 38.6 \\
\hline Al-Babtain ${ }^{\mathrm{e}}$ & 68 & 44.0 & 1,370 & 35 & 22 & 62.9 \\
\hline
\end{tabular}

General hospitals include the following specialties: general, vascular and urosurgery, internal medicine, pediatrics, maternity, adult, pediatric and neonatal intensive care units, special care baby unit, coronary care unit.

${ }^{\mathrm{a}}$ General teaching hospital. ${ }^{\mathrm{b}}$ Neurosurgery and pediatric surgery. ${ }^{\mathrm{c}}$ Ophthalmology. ${ }^{\mathrm{d}}$ Renal transplantation. ${ }^{\mathrm{e}}$ Burn and plastic surgery.

ateness of the agent. Analysis of the prescription was based on the recommendations of the local departmental policy. When the antibiotic was prescribed according to the policy-cited choice and/ or based on microbiological culture and sensitivity results, we considered it appropriate and then its dose, route of administration, frequency and duration were further evaluated. If more than one agent was prescribed for a specific condition, all aspects for each antibiotic were evaluated separately. A simplified version of the steps for reviewing the record to evaluate adherence to the hospital policy guidelines is given in figure 1 .

Full adherence (compliance) was defined as prescription of a justifiably indicated antibiotic fulfilling the correct choice, dose, route, frequency and duration of therapy. Nonadherence (noncompliance) to the policy was considered when there was prescription of a nonindicated antibiotic (overprescription), divergence from the advisable antibiotic, or failure to have full concordance with other aspects of the dose, route, frequency or duration. When the diagnosis was unclear in the patient record or the condition which necessitated antibiotic use was not mentioned in the policy, evaluation for adherence could not be performed and was considered as nonassessable.

Compliance was calculated as the percentage of compliant prescriptions divided by compliant plus noncompliant plus nonassessable ones as follows: compliance $=[$ (number of compliant prescriptions)/(number of compliant + noncompliant + nonassessable prescriptions) $] \times 100$.

\section{Sample Size Calculation}

A sample size of 2,300 records was determined on an assumption that antibiotics are prescribed in $40 \%$ of the total number of hospital discharges based on results of the pilot survey at $5 \%$ significance level and power of $80 \%$ using Epi Info ${ }^{\mathrm{TM}}$ software.

\section{Statistical Analysis}

Data were checked for completeness, accuracy and normality, then analyzed using the SPSS version 17 for Windows (SPSS Inc., Chicago, Ill., USA) by one of the authors (A.S.). Qualitative variables were expressed as numbers and percentages while quantitative variables were expressed as median and interquartile range. Mann-Whitney test was used to compare the median age and hospital stay. A p value $<0.05$ was considered as statistically significant.

\section{Results}

Of 2,300 records, 2,232 were reviewed and 68 (3\%) were missing. Of the 2,232 records, 1,112 (49.8\%) had 1,528 antibiotic prescriptions. Patients who received antibiotics were significantly younger than those who did not (median age: 26.3 vs. 29.8 years, $\mathrm{p}<0.001$ ) and their hospital stay was significantly longer (median: 4 vs. 2 days, $\mathrm{p}<0.001)$. Age, gender and median hospital stay of patients are presented in table 2 .

Regarding antibiotic indications, antibiotics were 'indicated' in 1,099 (71.9\%) of which 936 were evaluated and 163 despite being indicated were not evaluated due to conditions not mentioned in the policy; 'not indicated' in $382(25 \%)$ and 'not evaluated' in 47 (3.1\%) due to unclear diagnosis.

With respect to adherence to local policies, antibiotic prescriptions were evaluated as follows: fully adherent 
Fig. 1. Steps for reviewing the records to assess adherence to antibiotic policy guidelines.

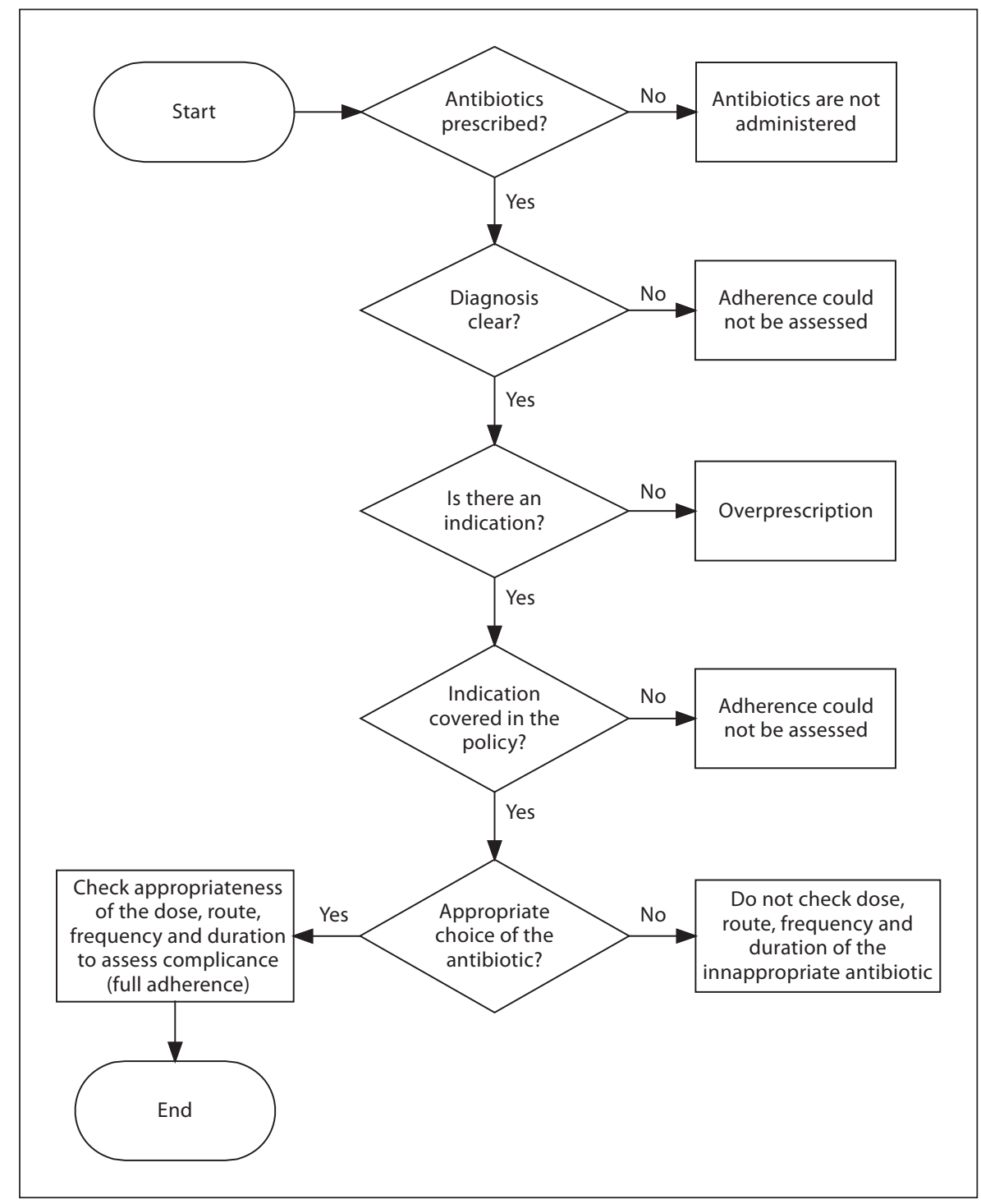

Table 2. Age, gender and hospital stay of study patients

\begin{tabular}{|c|c|c|c|c|c|}
\hline \multirow[t]{2}{*}{ Patient characteristic } & & \multicolumn{4}{|c|}{ Review of records for antibiotic prescription } \\
\hline & & $\begin{array}{l}\text { with antibiotics } \\
(\mathrm{n}=1,112)\end{array}$ & $\begin{array}{l}\text { no antibiotics } \\
(\mathrm{n}=1,120)\end{array}$ & $\begin{array}{l}\text { total } \\
(\mathrm{n}=2,232)\end{array}$ & $\mathrm{p}$ value \\
\hline Age, years & median (IQR) & $26.3(34.6)$ & $29.8(35.1)$ & $27.9(34.9)$ & $<0.001$ \\
\hline Hospital stay, days & median (IQR) & $4.0(4.0)$ & $2.0(3.0)$ & $3.0(3.0)$ & $<0.001$ \\
\hline \multirow[t]{2}{*}{ Gender } & male, $\mathrm{n}(\%)$ & $561(50.5)$ & $527(47.0)$ & $1,088(48.7)$ & 0.109 \\
\hline & female, n (\%) & $551(49.5)$ & $593(53.0)$ & $1,144(51.3)$ & \\
\hline
\end{tabular}

$\mathrm{IQR}=$ Interquartile range. 
Fig. 2. Situational analysis of antibiotic prescriptions.

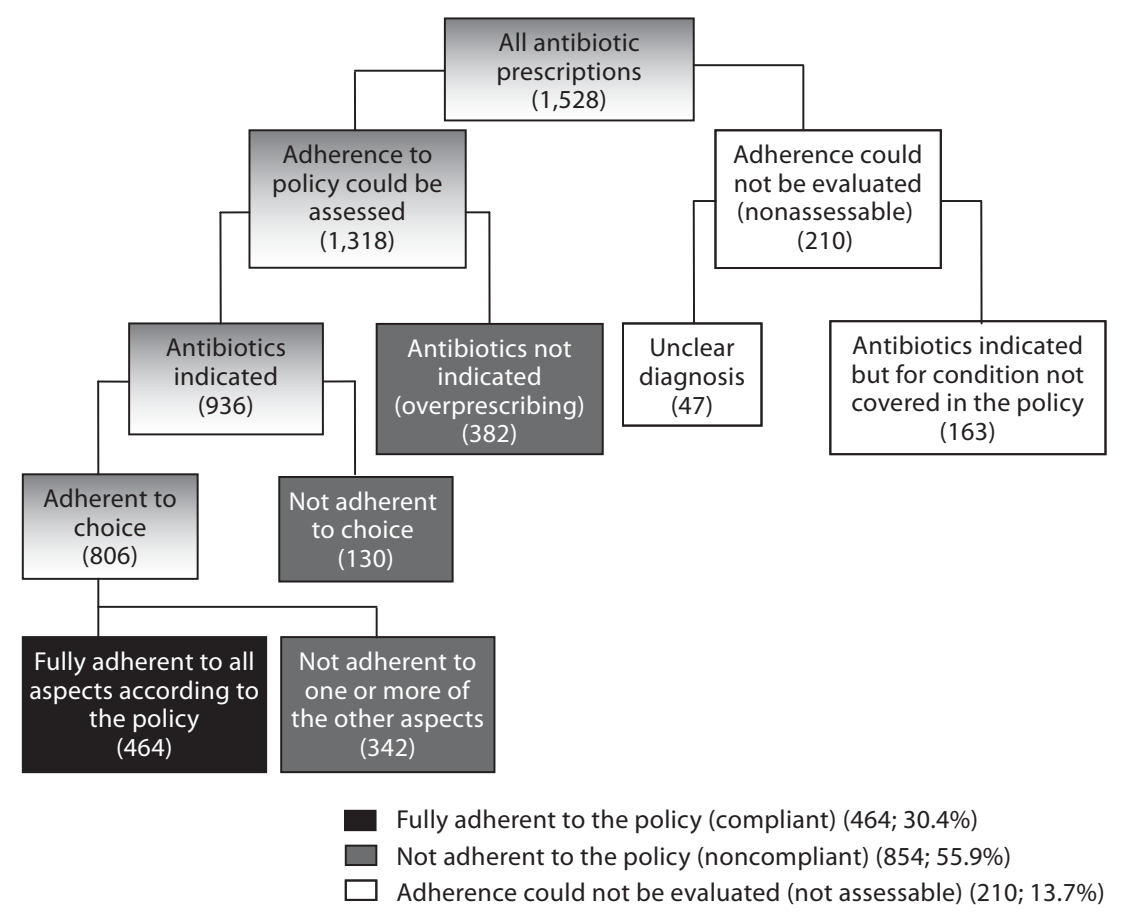

(compliant) in 464 (30.4\%), nonadherent (noncompliant) in 854 (55.9\%) and nonassessable in 210 (13.7\%). The situational analysis of all antibiotic prescriptions is illustrated in figure 2. The choice of the antibiotic was appropriate in 806 (52.7\%). Adherence to the route of administration was achieved in 768/806 (95.3\%), dose in 758 (94\%), frequency in 746 (92.6\%) and to duration in 608 (75.4\%).

Surgical prophylaxis was the leading indication for antibiotic prescribing (735 prescriptions) distributed as follows: 'indicated': 545; 'not indicated': 190, as shown in table 3. Of the 'indicated' surgical prophylaxis, the correct choice of agent was achieved in 486 (89.2\%) while full adherence to prophylaxis guidelines was achieved in 272 (49.9\%), which equals $37 \%$ of all surgical prophylaxis.

Percentage of appropriateness of the agent varied from one indication category to another: bloodstream infection: $22 / 24$ (91.7\%); lower respiratory tract infection: 86/94 (91.5\%); urinary tract infection: 79/90 (87.8\%); and skin and soft tissue infection: 29/39 (74.4\%). Nevertheless, full adherence to policy guidelines was $66.7 \%$ in bloodstream infection, $48.9 \%$ in lower respiratory tract infection, $47.8 \%$ in urinary tract infection and $56.4 \%$ in skin and soft tissue infection. Distribution of antibiotic prescriptions by indication and level of adherence to the policy are presented in table 3 .

\section{Discussion}

There is a mounting universal public health concern related to higher rates of bacterial antimicrobial resistance. The misuse of antibiotics contributes to this dilemma [14]. In our study, the $25 \%$ nonindicated antibiotic prescriptions was within the range of $15.5-72 \%$ reported in other studies [15-18]. The unwarranted prescription of antibiotics among physicians could be due to inaccurate diagnosis, imprecise recognition of conditions that can be treated with antibiotics, and concerns of a poor clinical outcome when antibiotics are not given [19]. Fear of legal action by patients might have led to the tendency of self-protection [9].

The proper antibiotic choice of $52.7 \%$ of all prescriptions in this study was lower (67\%) than that reported by Mol et al. [20]. Equally important, a previous study in neonatal units of four hospitals in Kuwait had shown inappropriate choice of empirical antibiotics in $76 \%$ of cases as evidenced by the antibiotic susceptibility of the reported organisms [21].

Surgical prophylaxis was the commonest indication for antibiotic prescribing in our study, comparable to that of Tourmousoglou et al. [22]. Figures of full adherence to surgical prophylaxis guidelines varied in the literature 
Table 3. Distribution of antibiotic prescriptions by indication and level of adherence to the policy

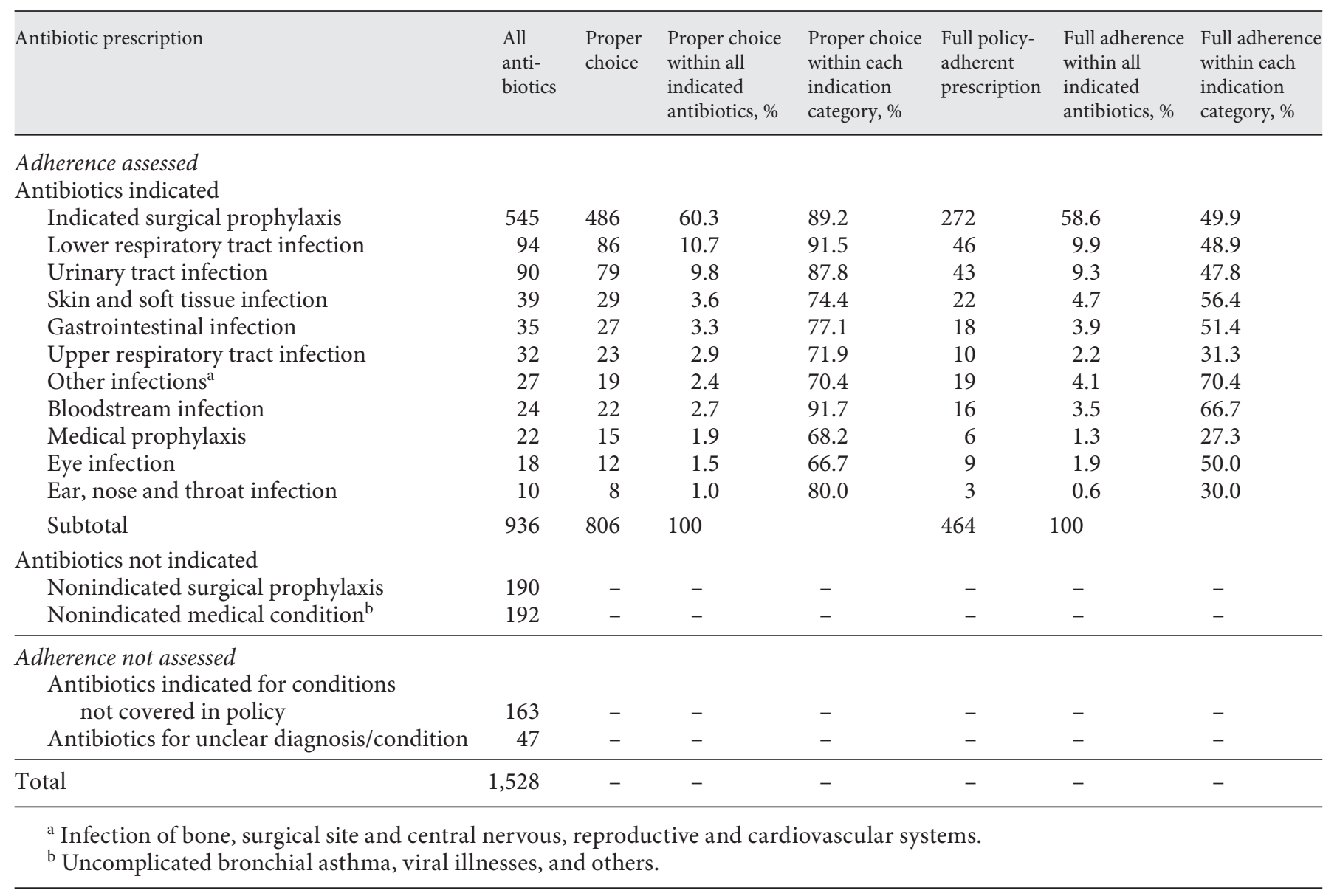

[22-24]. Lower percentages were reported in other studies $[18,25]$. The difference in these findings could be due to differences in the method in each study.

The rationale for prescribing a nonindicated surgical prophylaxis in our study might be the fear of complications, sense of more self-assurance of the surgeons when the patient receives antibiotic, or nonacquaintance with the policy recommendations. Therefore, it is crucial for surgeons to understand the true role of prophylaxis, and the drawbacks when used inappropriately. They should be aware of the optimal prophylactic antibiotic, when and for how long it should be given. The key obstacles to local policy adherence need to be explored.

In general, organizational obstacles such as delay in performing or lack of a system to review the required investigations, inconsistent antibiotic availability, and work intensity in the presence of other issues like weak triage system possibly play a role [26]. Likewise, lack of senior support for junior staff or no audit of the prescribed an- tibiotic regimen and failure to change a familiar wardpopular antibiotic or combination of antibiotics have been shown to influence the empirical and other policyrelated guidelines $[27,28]$.

The appropriate use of antimicrobials is an essential part of patient safety and deserves careful oversight and guidance. Given the association between antimicrobial use and the selection of resistant pathogens, the frequency of inappropriate antimicrobial use is often used as a surrogate marker for the avoidable impact on antimicrobial resistance. The combination of effective antimicrobial stewardship with a comprehensive infection control program has been shown to limit the emergence and transmission of antimicrobial-resistant bacteria [25]. The primary goal of antimicrobial stewardship is to optimize clinical outcomes while minimizing unintended consequences of antimicrobial use that include toxicity, the selection of pathogenic organisms (such as Clostridium difficile), and the emergence of resistance. The secondary 
goal is to reduce health care costs without adversely impacting quality of care [25].

New antibiotic stewardship tools, such as the use of a blood biomarker-derived treatment algorithm, have been shown to reduce antibiotic consumption. The biomarker, procalcitonin, that is released rapidly into the bloodstream in the presence of an infection, has demonstrated utility in guiding decisions regarding antimicrobial therapy [29]. Introduction of such biomarkers in treatment guidelines in Kuwait could minimize indiscriminate use of antibiotics.

To improve adherence to antibiotic policy, we recommend that more efficient control measures should be developed and implemented which include availability of the guidelines on the hospital information system, monitoring antibiotic misuse through repetitive audits and continuous education of the physicians to raise their awareness of proper prescription. Policies should be revised and periodically updated to cover all conditions treatable with antibiotics.

The study has some limitations. It was a descriptive study for levels of adherence to hospitals' antibiotic policies but did not explore different factors influencing adherence rates. Differences in the content of antibiotic policies between the hospitals included were not studied and data on microbiology analysis were not presented.

\section{Conclusions}

The developed antibiotic policies have not been adequately implemented. This suboptimal adherence to antibiotic policies may have had an impact on antibioticresistant rates and healthcare-associated infection incidence rates. Although there was good adherence to the proper antibiotic choice, failure to comply with appropriate dosing, route, frequency and duration of treatment as well as overprescribing were the reasons for poor adherence to the policy as a whole.

\section{Acknowledgments}

We thank the infection control physicians for their help with data collection. We also extend our thanks to the statisticians and data entry operators at the Department of Health Information and Medical Records, Ministry of Health, Kuwait.

The study was supported in part by the Ministry of Health, grant number 163/2008 dedicated to the Kuwait National Campaign for Proper Use of Antibiotics in 2009.

\section{References}

$>1$ Gould IM: A review of the role of antibiotic policies in the control of antibiotic resistance. J Antimicrob Chemother 1999;43: 459-465.

$\checkmark 2$ Hecker MT, Aron DC, Patel NP, Lehmann MK, Donskey CJ: Unnecessary use of antimicrobials in hospitalized patients: current patterns of misuse with an emphasis on the antianaerobic spectrum of activity. Arch Intern Med 2003;163:972-978.

-3 Rüttimann S, Keck B, Hartmeier C, Maetzel A, Bucher HC: Long-term antibiotic cost savings from a comprehensive intervention program in a medical department of a university-affiliated teaching hospital. Clin Infect Dis 2004;38:348-356.

4 McIntosh J, Earnshaw JJ: Antibiotic prophylaxis for the prevention of infection after major limb amputation. Eur J Vasc Endovasc Surg 2009;37:696-703.

5 Prokuski L: Prophylactic antibiotics in orthopaedic surgery. J Am Acad Orthop Surg 2008; 16:283-293.
6 Lawton RM, Fridkin SK, Gaynes RP, McGowan JE Jr: Practices to improve antimicrobial use at 47 US hospitals: the status of the 1997 SHEA/IDSA position paper recommendations. Society for Healthcare Epidemiology of America/Infectious Diseases Society of America. Infect Control Hosp Epide miol 2000;21:256-259.

$\checkmark 7$ Menendez R, Ferrando D, Valles JM, Vallterra J: Influence of deviation from guidelines on the outcome of community-acquired pneumonia. Chest 2002;122:612-617.

$>8$ Pedersen G, Schønheyder HC, Sørensen HT: Antibiotic therapy and outcome of monomicrobial gram-negative bacteraemia: a 3-year population-based study. Scand J Infect Dis 1997;29:601-606.

$>9$ Halm EA, Atlas SJ, Borowsky LH, Benzer TI, Metlay JP, Chang YC, Singer DE: Understanding physician adherence with a pneumonia practice guideline: effects of patient, system, and physician factors. Arch Intern Med 2000;160:98-104.
Fijn R, Chow MC, Schuur PM, De Jong-Van den Berg LT, Brouwers JR: Multicentre evaluation of prescribing concurrence with antiinfective guidelines: epidemiological assessment of indicators. Pharmacoepidemiol Drug Saf 2002;11:361-372.

11 van de Beek D, de Gans J, Spanjaard L, Vermeulen M, Dankert J: Antibiotic guidelines and antibiotic use in adult bacterial meningitis in The Netherlands. J Antimicrob Chemother 2002;49:661-666.

12 Davey P, Brown E, Fenelon L, Finch R, Gould I, Hartman G, Holmes A, Ramsay C, Taylor E, Wilcox M, Wiffen P: Interventions to improve antibiotic prescribing practices for hospital inpatients. Cochrane Database Syst Rev 2005;4:CD003543.

13 Horan TC, Andrus M, Dudeck MA: CDC/ NHSN surveillance definition of health care-associated infection and criteria for specific types of infections in the acute care setting. Am J Infect Control 2008;36:309332 
14 Costelloe C, Metcalfe C, Lovering A, Mant D, Hay AD: Effect of antibiotic prescribing in primary care on antimicrobial resistance in individual patients: systematic review and meta-analysis. BMJ 2010;340:c2096.

15 Fonseca LG, de Oliveira Conterno L: Audit of antibiotic use in a Brazilian university hospital. Braz J Infect Dis 2004;8:272-280.

$\checkmark 16$ Pulcini C, Cua E, Lieutier F, Landraud L, Dellamonica P, Roger PM: Antibiotic misuse: a prospective clinical audit in a French university hospital. Eur J Clin Microbiol Infect Dis 2007;26:277-280.

$\checkmark 17$ Aswapokee N, Vaithayapichet S, Heller RF: Pattern of antibiotic use in medical wards of a university hospital, Bangkok, Thailand. Rev Infect Dis 1990;12:136-141.

- 18 Al-Ghamdi S, Gedebou M, Bilal NE: Nosocomial infections and misuse of antibiotics in a provincial community hospital, Saudi Arabia. J Hosp Infect 2002;50:115-121.

19 Davis DA, Taylor-Vaisey A: Translating guidelines into practice: a systematic review of theoretic concepts, practical experience and research evidence in the adoption of clinical practice guidelines. CMAJ 1997;157: 408-416.
20 Mol PG, Wieringa JE, Nannanpanday PV, Gans RO, Degener JE, Laseur M, HaaijerRuskamp FM: Improving compliance with hospital antibiotic guidelines: a time-series intervention analysis. J Antimicrob Chemother 2005;55:550-557.

21 Al-Sawan RM, Al-Saleh Q, Al-Alfy AA, AlEsaa M: Misuse of antimicrobial agents in neonatal units: a cross-sectional survey in Kuwait. Med Princ Pract 1999;8:119-125.

22 Tourmousoglou CE, Yiannakopoulou E, Kalapothaki V, Bramis J, St Papadopoulos J: Adherence to guidelines for antibiotic prophylaxis in general surgery: a critical appraisal. J Antimicrob Chemother 2008;61: 214-218.

23 van Kasteren ME, Kullberg BJ, de Boer AS, Mintjes-de Groot J, Gyssens IC: Adherence to local hospital guidelines for surgical antimicrobial prophylaxis: a multicentre audit in Dutch hospitals. J Antimicrob Chemother 2003;51:1389-1396.

24 Heineck I, Ferreira MB, Schenkel EP: Prescribing practice for antibiotic prophylaxis for 3 commonly performed surgeries in a teaching hospital in Brazil. Am J Infect Control 1999;27:296-300.
25 Dellit TH, Owens RC, McGowan JE Jr, Gerding DN, Weinstein RA, Burke JP, Huskins WC, Paterson DL, Fishman NO, Carpenter CF, Brennan PJ, Billeter M, Hooton TM: Infectious Diseases Society of America and the Society for Healthcare Epidemiology of America guidelines for developing an institutional program to enhance antimicrobial stewardship. Clin Infect Dis 2007;44:159-177.

26 Barlow G, Nathwani D, Myers E, Sullivan F, Stevens N, Duffy R, Davey P: Identifying barriers to the rapid administration of appropriate antibiotics in communityacquired pneumonia. J Antimicrob Chemother 2008;61:442-451.

27 Hulscher ME, Grol RP, van der Meer JW: Antibiotic prescribing in hospitals: a social and behavioural scientific approach. Lancet Infect Dis 2010;10:167-175.

-28 Schouten JA, Hulscher ME, Natsch S, Kullberg BJ, van der Meer JW, Grol RP: Barriers to optimal antibiotic use for community-acquired pneumonia at hospitals: a qualitative study. Qual Saf Health Care 2007;16:143-149.

29 Lawrence KL, Kollef MH: Antimicrobial stewardship in the intensive care unit: advances and obstacles. Am J Respir Crit Care Med 2009;179:434-438. 